\section{Review}

Correspondence

Andrej Weintraub

Andrej.weintraub@ki.se

\title{
Enteroaggregative Escherichia coli: epidemiology, virulence and detection
}

\author{
Andrej Weintraub \\ Karolinska Institute, Department of Laboratory Medicine, Division of Clinical Bacteriology, \\ Karolinska University Hospital, Huddinge, 14186 Stockholm, Sweden
}

\begin{abstract}
Enteroaggregative Escherichia coli (EAEC) is a subgroup of diarrhoeagenic E. coli (DEC) that during the past decade has received increasing attention as a cause of watery diarrhoea, which is often persistent. EAEC have been isolated from children and adults worldwide. As well as sporadic cases, outbreaks of EAEC-caused diarrhoea have been described. The definition of EAEC is the ability of the micro-organism to adhere to epithelial cells such as HEp-2 in a very characteristic 'stacked-brick' pattern. Although many studies searching for specific virulence factor(s) unique for this category of DEC have been published it is still unknown why the EAEC cause persistent diarrhoea. In addition, the aggregative property of EAEC causes a lot of problems in serotyping due to the cells auto-agglutinating. The gold standard for identification of EAEC includes isolation of the agent and an adherence assay using tissue culture, viz. HEp-2 cells. This assay is in most cases reliable; however, emergence of 'atypical' EAEC has been described in several publications. In addition, the HEp-2 assay is time consuming, demands a tissue culture lab and trained staff. Several molecular biological assays have been described, however, none show $100 \%$ specificity.
\end{abstract}

\section{Introduction}

Escherichia coli is the type species of the genus Escherichia that contains mostly motile Gram-negative bacilli that fall within the family Enterobacteriaceae. It is the predominant facultative anaerobe of the human colonic flora. The organism typically colonizes the infant gastrointestinal tract within hours of life, and thereafter E. coli and the host derive mutual benefit for decades (Kaper et al., 2004). However, there are several highly adapted E. coli clones that have acquired specific virulence factors, which increase their ability to adapt to new niches and allow them to cause a broad spectrum of diseases. Three general clinical syndromes can result from infection with pathogenic $E$. coli strains: enteric/diarrhoeal disease, urinary tract infection and sepsis/meningitis (Nataro \& Kaper, 1998). As long as these bacteria do not acquire genetic elements encoding virulence factors, they remain benign commensals. Strains that acquire 'foreign' DNA encoding enterotoxins, adhesins or invasion factors become virulent and can cause either a plain, watery diarrhoea or inflammatory dysentery.

\section{Enteroaggregative E. coli}

Among the E. coli causing intestinal diseases, there are six well-described categories: enteroaggregative E. coli (EAEC), diffusely adherent E. coli (DAEC), enteroinvasive E. coli (EIEC), enteropathogenic E. coli (EPEC), enterohaemorrhagic E. coli (EHEC) and enterotoxigenic E. coli (ETEC) (Nataro \& Kaper, 1998). These categories have virulence attributes that help bacteria to cause diseases by different mechanisms. The EIEC, EHEC and ETEC are defined as E. coli strains possessing specific virulence attributes, including different toxins, invasion plasmid and colonization factors. Almost half a century ago, Ewing et al. (1963) determined that certain serotypes of $E$. coli were associated with outbreaks of diarrhoea. Strains belonging to these serotypes were referred to as EPEC. In 1979, Cravioto and colleagues described an in vitro assay based on the adhesion of the bacteria to HEp-2 cells showing that EPEC bind to the cells in a localized pattern (Cravioto et al., 1979). A few years later it was shown that adherent non-EPEC strains were associated with diarrhoea. These strains were called 'enteroadherent E. coli' (Cravioto et al., 1991; Mathewson et al., 1985, 1987). At the same time, Nataro et al. (1987) recognized two different phenotypes among the enteroadherent strains, i.e. diffuse and aggregative. The finding of Nataro was the first description of EAEC. The aggregative adherence is characterized by a 'stacked-brick' formation of bacterial cells attached to the HEp-2 cells (Nataro \& Kaper, 1998; Nataro et al., 1998). The basic strategy of EAEC seems to comprise colonization of the intestinal mucosa, probably predominantly that of the colon, followed by secretion of enterotoxins and cytotoxins (Nataro et al., 1998). Studies on human intestinal specimens indicate that EAEC induces mild, but significant, mucosal damage (Hicks et al., 1996). EAEC strains characteristically enhance mucus secretion from the mucosa, with trapping of the bacteria in a bacterium-mucus biofilm (Nataro \& Kaper, 1998). Two further observations support a role of mucus in EAEC pathogenesis: EAEC bound avidly in the rabbit in vitro 
model (Wanke et al., 1990) and volunteers fed EAEC strains excrete mucoid stools (Nataro et al., 1995). The formation of a heavy biofilm may be related to the diarrhoeagenicity of the organisms and, perhaps, to its ability to cause persistent colonization and diarrhoea. In addition to forming a mucous biofilm, many EAEC strains induce cytotoxic effects on the intestinal mucosa. In animal models infected with EAEC in rabbit and rat ileal loops, light microscopy showed some destructive lesions (Vial et al., 1988). EAEC also induced shortening of the villi, haemorrhagic necrosis of the villous tips, and a mild inflammatory response with oedema and mononuclear infiltration of the submucosa. Both light and electron microscopy showed adherent bacteria without the attaching and effacing lesion, which is characteristic of EPEC. The clinical features of EAEC diarrhoea are increasingly well defined in outbreaks, sporadic cases and the volunteer model. Typical illness is characterized by watery, mucoid, secretory diarrhoea with low-grade fever and little to no vomiting (Bhan et al., 1989b; Paul et al., 1994). However, up to one third of patients with EAEC diarrhoea had grossly bloody stools (Cravioto et al., 1991).

\section{Epidemiology \\ Developing countries}

A growing number of studies have supported the association of EAEC with diarrhoea in developing countries, most prominently in association with persistent diarrhoea (Bhan et al., 1989a, b, c; Fang et al., 1995; Lima et al., 1992). Several studies in children with diarrhoea have shown a significant difference in the prevalence of EAEC compared to the controls (Bhatnagar et al., 1993; Bouzari et al., 1994; Cravioto et al., 1991; Gonzalez et al., 1997; Nataro et al., 1987). EAEC and persistent diarrhoea syndrome have been consistently associated (Fang et al., 1995; Lima et al., 1992; Wanke et al., 1991). The increasing number of such reports and the rising proportion of diarrhoeal cases in which EAEC are implicated suggest that EAEC are important emerging agents of paediatric diarrhoea.

During the initial years after the discovery of EAEC there were a lot of doubts about the pathogenicity of this category of diarrhoeagenic E. coli (DEC) (Echeverria et al., 1992; Gomes et al., 1989). However, Nataro et al. (1995) showed that a reference strain of EAEC could cause diarrhoea in a volunteer study. In addition, a number of outbreaks have proven that at least some EAEC strains cause diarrhoea in humans. Furthermore, many case-control and cohort surveys of the past 15 years strongly suggest that EAEC is an important cause of diarrhoea in people of all ages in developing and industrialized countries. In a recent study from Vietnam by Vu Nguyen et al. (2006) it was shown that EAEC is more frequently associated with diarrhoea in children less than 2 years of age. In this study, 587 children of less than 5 years of age with diarrhoea and 249 agematched healthy controls were examined for, among other pathogens, EAEC. Of all identified EAEC strains in the diarrhoeal group, $87 \%$ were isolated from children less than 2 years of age. The corresponding figure for the control group was 39\% (Vu Nguyen et al., 2006). Many of the epidemiological surveys that identified EAEC as a diarrhoeal pathogen were done in developing countries. However, EAEC has been found to be associated with diarrhoea in developed countries as well.

\section{Developed countries}

In a Scandinavian case-control study the prevalence and the association of EAEC with diarrhoea was greater than for EPEC (Bhatnagar et al., 1993). Another study conducted in east London showed that EAEC could be recovered from children with acute and persistent diarrhoea (Chan et al., 1994). A clear association of EAEC with diarrhoea in children in Germany was shown by Huppertz et al. (1997) who recovered EAEC from $16(2 \%)$ of 798 children with diarrhoea but none from 580 healthy controls. Other European studies in children (Knutton et al., 2001; Presterl et al., 1999) also indicate that EAEC may be a leading cause of diarrhoeal disease in developed as well as developing countries. In a Serbian neonatal ward an outbreak of EAEC diarrhoea was described by Cobeljic et al. (1996) where 19 babies were affected and 3 of these patients got diarrhoea. One EAEC strain resistant to multiple antibiotics was implicated. In the largest reported outbreak so far, 2697 (40.6\%) Japanese children who ate infected school lunches had severe diarrhoea and EAEC was found in $10 \%$ of cases (Itoh et al., 1997). Several other outbreaks both in children and in adults have been described in the UK (Smith et al., 1997; Spencer et al., 1999), India (Pai et al., 1997) and France (Boudailliez et al., 1997; Morabito et al., 1998).

In a 1 year prospective Swedish study on enteropathogens in adult patients with diarrhoea and healthy control subjects, 105 of 760 patients with diarrhoea were positive for DEC. EAEC was present in 16 cases and was the second most common isolate among DEC surpassed only by ETEC (Svenungsson et al., 2000). Other studies have shown that this pathogen is an important cause of travellers' diarrhoea (Adachi et al., 2001; Gascón et al., 1998; Schultsz et al., 2000). However, documented reports are less common because EAEC is not sought in many studies. Travellers to all developing countries are at risk and if EAEC were sought in all laboratories, infection by this pathogen could explain over $25 \%$ of cases for which no pathogen is recovered (Adachi et al., 2001).

\section{Immunocompromised}

Diarrhoea is an important cause of morbidity in the immunocompromised. A wide range of pathogens is implicated in AIDS-associated diarrhoea, and in many cases a causative agent is not found. Case reports from Mayer \& Wanke (1995) described that EAEC could be recovered from diarrhoeal stools from AIDS patients. There have been other reports after epidemiological surveillance among HIV-positive patients (Mayer \& Wanke, 1995). 


\section{Virulence factors}

In order to cause diarrhoeal disease, EAEC adheres to intestinal mucosa, forms a mucoid biofilm and induces toxic effects on the intestinal mucosa that result in diarrhoea. The exact mechanism of pathogenesis is not fully understood; however, adhesins, toxins and several other factors have been implicated. Certain strains carry a high molecular weight plasmid associated with the aggregative adherence (Law et al., 1998; Vial et al., 1988), on which a number of virulence genes are located. These are (i) heat stable toxin-1 (EAST-1) (Savarino et al., 1991), (ii) aggregative adherence fimbriae I and II (AAF/I and AAF/II) (Nataro et al., 1992; Rich et al., 1999), as well as the AAF/III (Bernier et al., 2002). Also located on the plasmid are (i) transcriptional activator gene (Nataro et al., 1994, 1998), (ii) anti-aggregation protein gene (Sheikh et al., 2002), and (iii) anti-aggregation protein transporter gene (Baudry et al., 1990). In addition, the plasmid-encoded toxin (Eslava et al., 1998) and a cryptic ORF known as shf (Czeczulin et al., 1999) have been described. Other virulence factors that are believed to be associated with EAEC are 18 and $30 \mathrm{kDa}$ outermembrane adhesins (Chart et al., 1997; Debroy et al., 1995; Grover et al., 2001). In addition, different pathogenicity islands have been identified within the EAEC group, including Shigella she pathogenicity island, containing enterotoxin and mucinase genes (Henderson et al., 1999), and Yersinia high-pathogenicity island, containing the yersiniabactin siderophore gene (Schubert et al., 1998). Strains that carry the high molecular weight plasmid represent an important subgroup (Cerna et al., 2003; Elias et al., 2002) and may be regarded as 'typical EAEC'. However, EAEC is a heterogeneous group of E. coli (Czeczulin et al., 1999) and certain strains, although adherent to the HEp-2 cells in the stacked-brick mode, lack the high molecular weight plasmid and can be called 'atypical EAEC' (Cobeljic et al., 1996; Elias et al., 2002; Gioppo et al., 2000; Itoh et al., 1997).

\section{Identification - serotyping and molecular biology}

However, none of the above-described gene(s) is conserved among all of the EAEC and many are not unique to this category of DEC. Recently, Jenkins et al. (2006a) used several different probes to characterize EAEC strains. The results show that the majority of the HEp-2 positive strains were also positive for the anti-aggregation protein transporter gene described by Baudry et al. (1990) against which Schmidt and colleagues developed a PCR assay in 1995 (Schmidt et al., 1995). Overall, 143 EAEC strains were analysed and 128 (90\%) were positive for the anti-aggregation protein transporter gene (Jenkins et al., 2006a). However, $10 \%$ of the strains verified by HEp-2 assay were negative in the PCR assay. This makes it difficult to provide a genotypic definition for EAEC and to design specific molecular biological assays for the detection of this pathotype. In addition, serotyping of EAEC is a problem. Due to their aggregative phenotype, many of the strains auto-agglutinate and are often described in the literature as non-typable or as O-rough. It is also well established that the EAEC group is highly heterogeneous. Huppertz et al. (1997) analysed EAEC from German children and found that of 14 typable isolates all belonged to different serotypes. In another study in the UK, 97 EAEC strains were serotyped to 40 different O-types. However, the remaining 121 EAEC isolates were non-typable (Food Standards Agency, 2000). In a study by Jenkins et al. (2006a), 93 out of 143 EAEC strains could be serotyped and belonged to as many as 47 different serotypes. This shows that serotyping, although useful in the characterization of other DEC, is of little value in the diagnosis of EAEC. As mentioned earlier, the HEp-2 adherence test is the gold standard for the identification of EAEC. This test requires specialized facilities and can therefore only be conducted in reference laboratories, and strict adherence to protocol is required (Haider et al., 1992; Vial et al., 1990). Several attempts have been made to develop a molecular biological assay for the identification of EAEC. In 1990, Baudry and colleagues developed a DNA probe, CVD432, that was found to be $89 \%$ sensitive and $99 \%$ specific for EAEC (Baudry et al., 1990). Based on this probe, a PCR assay was developed by Schmidt et al. in 1995. This assay has been widely used since then. In search for additional virulence factors, several other assays have been described, none of which with has as high sensitivity and specificity as the one described in 1995. The problems in identification of EAEC have been clearly highlighted very recently (Jenkins et al., 2006b). The authors set up a multiplex PCR targeting three different genes: (i) the anti-aggregation protein transporter gene described by Baudry et al. (1990), (ii) the EAST gene (Savarino et al., 1991) and (iii) a chromosomal gene present in the phe $U$ pathogenicity island designated aggR-activated island (Jenkins et al., 2006b). The authors used this multiplex PCR to identify EAEC from patients in the community suffering from diarrhoea. They found that twice as many isolates were positive against at least one of the primers as compared to the HEp-2 adherence assay alone.

\section{Conclusion}

The HEp-2-adherence assay and/or the CVD432 standard probe represent the best means at present for detecting EAEC. However, it is clear that more sensitive, specific and practical methods are needed in order to improve the diagnosis of infected cases with EAEC and to understand the disease.

\section{Note from the editor-in-chief}

A review on EAEC by Huang and colleagues was published in the Journal of Medical Microbiology October 2006 issue (Huang et al., 2006) that concentrated on the epidemiology and pathogenic mechanisms of the bacterium. More recently a paper by Jenkins and colleagues (Jenkins et al., 2006b) has been published drawing attention to the difficulties in diagnosing EAEC infection by molecular methods. This mini review by Andrej Weintraub discusses the problem further. 


\section{References}

Adachi, J. A., Jiang, Z. D., Mathewson, J. J., Verenkar, M. P. Thompson, S., Martinez-Sandoval, F., Steffen, R., Ericsson, C. D. \& DuPont, H. L. (2001). Enteroaggregative Escherichia coli as a major etiologic agent in traveler's diarrhea in 3 regions of the world. Clin Infect Dis 32, 1706-1709.

Baudry, B., Savarino, S. J., Vial, P., Kaper, J. B. \& Levine, M. M. (1990). A sensitive and specific DNA probe to identify enteroaggregative Escherichia coli, a recently discovered diarrheal pathogen. J Infect Dis 161, 1249-1251.

Bernier, C., Gounon, P. \& Le Bouguenec, C. (2002). Identification of an aggregative adhesion fimbria (AAF) type III-encoding operon in enteroaggregative Escherichia coli as a sensitive probe for detecting the AAF-encoding operon family. Infect Immun 70, 4302-4311.

Bhan, M. K., Bhandari, N., Sazawal, S., Clemens, J., Raj, P., Levine, M. M. \& Kaper, J. B. (1989a). Descriptive epidemiology of persistent diarrhoea among young children in rural northern India. Bull World Health Organ 67, 281-288.

Bhan, M. K., Raj, P., Levine, M. M., Kaper, J. B., Bhandari, N., Srivastava, R., Kumar, R. \& Sazawal, S. (1989b). Enteroaggregative Escherichia coli associated with persistent diarrhea in a cohort of rural children in India. J Infect Dis 159, 1061-1064.

Bhan, M. K., Sazawal, S., Raj, P., Bhandari, N., Kumar, R., Bhardwaj, Y., Shrivastava, R. \& Bhatnagar, S. (1989c). Aggregative Escherichia coli, Salmonella, and Shigella are associated with increasing duration of diarrhea. Indian J Pediatr 56, 81-86.

Bhatnagar, S., Bhan, M. K., Sommerfelt, H., Sazawal, S., Kumar, R. \& Saini, S. (1993). Enteroaggregative Escherichia coli may be a new pathogen causing acute and persistent diarrhea. Scand J Infect Dis $\mathbf{2 5}$, 579-583.

Boudailliez, B., Berquin, P., Mariani-Kurkdjian, P., llef, D., Cuvelier, B., Capek, I., Tribout, B., Bingen, E. \& Piussan, C. (1997). Possible person-to-person transmission of Escherichia coli O111-associated hemolytic uremic syndrome. Pediatr Nephrol 11, 36-39.

Bouzari, S., Jafari, A., Farhoudi-Moghaddam, A. A., Shokouhi, F. \& Parsi, M. (1994). Adherence of non-enteropathogenic Escherichia coli to HeLa cells. J Med Microbiol 40, 95-97.

Cerna, J. F., Nataro, J. P. \& Estrada-Garcia, T. (2003). Multiplex PCR for detection of three plasmid-borne genes of enteroaggregative Escherichia coli strains. J Clin Microbiol 41, 2138-2140.

Chan, K. N., Phillips, A. D., Knutton, S., Smith, H. R. \& Walker-Smith, J. A. (1994). Enteroaggregative Escherichia coli: another cause of acute and chronic diarrhoea in England? J Pediatr Gastroenterol Nutr 18, 87-91.

Chart, H., Spencer, J., Smith, H. R. \& Rowe, B. (1997). Magnesium ions are required for HEp-2 cell adhesion by enteroaggregative strains of Escherichia coli O126: H27 and O44:H18. FEMS Microbiol Lett 148, 49-52.

Cobeljic, M., Miljkovic-Selimovic, B., Paunovic-Todosijevic, D., Velickovic, Z., Lepsanovic, Z., Zec, N., Savic, D., Ilic, R., Konstantinovic, S. \& other authors (1996). Enteroaggregative Escherichia coli associated with an outbreak of diarrhoea in a neonatal nursery ward. Epidemiol Infect 117, 11-16.

Cravioto, A., Gross, R. J., Scotland, S. M. \& Rowe, B. (1979). An adhesive factor found in strains of Escherichia coli belonging to the traditional enteropathogenic serotypes. Curr Microbiol 3, 95-99.

Cravioto, A., Tello, A., Navarro, A., Ruiz, J., Villafan, H., Uribe, F. \& Eslava, C. (1991). Association of Escherichia coli HEp-2 adherence patterns with type and duration of diarrhoea. Lancet 337, 262-264.

Czeczulin, J. R., Whittam, T. S., Henderson, I. R., Navarro-Garcia, F. \& Nataro, J. P. (1999). Phylogenetic analysis of enteroaggregative and diffusely adherent Escherichia coli. Infect Immun 67, 2692-2699.
Debroy, C., Yealy, J., Wilson, R. A., Bhan, M. K. \& Kumar, R. (1995). Antibodies raised against the outer membrane protein interrupt adherence of enteroaggregative Escherichia coli. Infect Immun 63, 2873-2879.

Echeverria, P., Serichantalerg, O., Changchawalit, S., Baudry, B., Levine, M. M., Orskov, F. \& Orskov, I. (1992). Tissue culture-adherent Escherichia coli in infantile diarrhea. J Infect Dis 165, 141-143.

Elias, W. P., Barros, S. F., Moreira, C. G., Trabulsi, L. R. \& Gomes, T. A. (2002). Enteroaggregative Escherichia coli strains among classical enteropathogenic Escherichia coli O serogroups. J Clin Microbiol 40, 3540-3541.

Eslava, C., Navarro-Garcia, F., Czeczulin, J. R., Henderson, I. R., Cravioto, A. \& Nataro, J. P. (1998). Pet, an autotransporter enterotoxin from enteroaggregative Escherichia coli. Infect Immun 66, 3155-3163.

Ewing, W. H., Davis, B. R. \& Montague, T. S. (1963). Studies on the Occurence of Escherichia Coli Serotypes Associated with Diarrheal Disease, pp. 1-38. Atlanta, GA: US Department of Health, Education and Welfare, Public Health Service, CDC.

Fang, G. D., Lima, A. A., Martins, C. V., Nataro, J. P. \& Guerrant, R. L. (1995). Etiology and epidemiology of persistent diarrhea in northeastern Brazil: a hospital-based, prospective, case-control study. J Pediatr Gastroenterol Nutr 21, 137-144.

Food Standards Agency (2000). A Report of the Study of Infectious Intestinal Disease in England. London: The Stationery Office.

Gascón, J., Vargas, M., Quinto, L., Corachan, M., Jimenez de Anta, M. T. \& Vila, J. (1998). Enteroaggregative Escherichia coli strains as a cause of traveler's diarrhea: a case-control study. J Infect Dis 177, 1409-1412.

Gioppo, N. M., Elias, W. P., Jr, Vidotto, M. C., Linhares, R. E., Saridakis, H. O., Gomes, T. A., Trabulsi, L. R. \& Pelayo, J. S. (2000). Prevalence of HEp-2 cell-adherent Escherichia coli and characterisation of enteroaggregative E. coli and chain-like adherent E. coli isolated from children with and without diarrhoea, in Londrina, Brazil. FEMS Microbiol Lett 190, 293-298.

Gomes, T. A., Blake, P. A. \& Trabulsi, L. R. (1989). Prevalence of Escherichia coli strains with localized, diffuse, and aggregative adherence to HeLa cells in infants with diarrhea and matched controls. J Clin Microbiol 27, 266-269.

Gonzalez, R., Diaz, C., Marino, M., Cloralt, R., Pequeneze, M. \& Perez-Schael, I. (1997). Age-specific prevalence of Escherichia coli with localized and aggregative adherence in Venezuelan infants with acute diarrhea. J Clin Microbiol 35, 1103-1107.

Grover, V., Ghosh, S., Sharma, N., Chakraborti, A., Majumdar, S. \& Ganguly, N. K. (2001). Characterization of a galactose specific adhesin of enteroaggregative Escherichia coli. Arch Biochem Biophys 390, 109-118.

Haider, K., Faruque, S. M., Albert, M. J., Nahar, S., Neogi, P. K. \& Hossain, A. (1992). Comparison of a modified adherence assay with existing assay methods for identification of enteroaggregative Escherichia coli. J Clin Microbiol 30, 1614-1616.

Henderson, I. R., Czeczulin, J., Eslava, C., Noriega, F. \& Nataro, J. P. (1999). Characterization of Pic, a secreted protease of Shigella flexneri and enteroaggregative Escherichia coli. Infect Immun 67, 5587-5596.

Hicks, S., Candy, D. C. \& Phillips, A. D. (1996). Adhesion of enteroaggregative Escherichia coli to pediatric intestinal mucosa in vitro. Infect Immun 64, 4751-4760.

Huang, D. B., Mohanty, A., DuPont, H. L., Okhuysen, P. C. \& Chiang, T. (2006). A review of an emerging enteric pathogen: enteroaggregative Escherichia coli. J Med Microbiol 55, 1303-1311.

Huppertz, H. I., Rutkowski, S., Aleksic, S. \& Karch, H. (1997). Acute and chronic diarrhoea and abdominal colic associated with enteroaggregative Escherichia coli in young children living in western Europe. Lancet 349, 1660-1662. 
Itoh, Y., Nagano, I., Kunishima, M. \& Ezaki, T. (1997). Laboratory investigation of enteroaggregative Escherichia coli $\mathrm{O}$ untypeable: $\mathrm{H} 10$ associated with a massive outbreak of gastrointestinal illness. J Clin Microbiol 35, 2546-2550.

Jenkins, C., Chart, H., Willshaw, G. A., Cheasty, T. \& Smith, H. R. (2006a). Genotyping of enteroaggregative Escherichia coli and identification of target genes for the detection of both typical and atypical strains. Diagn Microbiol Infect Dis 55, 13-19.

Jenkins, C., Tembo, M., Chart, H., Cheasty, T., Willshaw, G. A., Phillips, A. D., Tompkins, D. \& Smith, H. (2006b). Detection of enteroaggregative Escherichia coli in faecal samples from patients in the community with diarrhoea. J Med Microbiol 55, 1493-1497.

Kaper, J. B., Nataro, J. P. \& Mobley, H. L. (2004). Pathogenic Escherichia coli. Nat Rev Microbiol 2, 123-140.

Knutton, S., Shaw, R., Phillips, A. D., Smith, H. R., Willshaw, G. A., Watson, P. \& Price, E. (2001). Phenotypic and genetic analysis of diarrhea-associated Escherichia coli isolated from children in the United Kingdom. J Pediatr Gastroenterol Nutr 33, 32-40.

Law, D. \& Chart, H. (1998). Enteroaggregative Escherichia coli. J Appl Microbiol 84, 685-697.

Lima, A. A., Fang, G., Schorling, J. B., de Albuquerque, L., McAuliffe, J. F., Mota, S., Leite, R. \& Guerrant, R. L. (1992). Persistent diarrhea in northeast Brazil: etiologies and interactions with malnutrition. Acta Paediatr Suppl 381, 39-44.

Mathewson, J. J., Johnson, P. C., DuPont, H. L., Morgan, D. R., Thornton, S. A., Wood, L. V. \& Ericsson, C. D. (1985). A newly recognized cause of travelers' diarrhea: enteroadherent Escherichia coli. J Infect Dis 151, 471-475.

Mathewson, J. J., Oberhelman, R. A., Dupont, H. L., Javier de la Cabada, F. \& Garibay, E. V. (1987). Enteroadherent Escherichia coli as a cause of diarrhea among children in Mexico. J Clin Microbiol 25, 1917-1919.

Mayer, H. B. \& Wanke, C. A. (1995). Enteroaggregative Escherichia coli as a possible cause of diarrhea in an HIV-infected patient. $N$ Engl J Med 332, 273-274.

Morabito, S., Karch, H., Mariani-Kurkdjian, P., Schmidt, H., Minelli, F., Bingen, E. \& Caprioli, A. (1998). Enteroaggregative, Shiga toxinproducing Escherichia coli $\mathrm{O} 111: \mathrm{H} 2$ associated with an outbreak of hemolytic-uremic syndrome. J Clin Microbiol 36, 840-842.

Nataro, J. P. \& Kaper, J. B. (1998). Diarrheagenic Escherichia coli. Clin Microbiol Rev 11, 142-201.

Nataro, J. P., Kaper, J. B., Robins-Browne, R., Prado, V., Vial, P. \& Levine, M. M. (1987). Patterns of adherence of diarrheagenic Escherichia coli to HEp-2 cells. Pediatr Infect Dis J 6, 829-831.

Nataro, J. P., Deng, Y., Maneval, D. R., German, A. L., Martin, W. C. \& Levine, M. M. (1992). Aggregative adherence fimbriae I of enteroaggregative Escherichia coli mediate adherence to HEp-2 cells and hemagglutination of human erythrocytes. Infect Immun 60, 2297-2304. Nataro, J. P., Yikang, D., Yingkang, D. \& Walker, K. (1994). AggR, a transcriptional activator of aggregative adherence fimbria I expression in enteroaggregative Escherichia coli. J Bacteriol 176, 4691-4699.

Nataro, J. P., Deng, Y., Cookson, S., Cravioto, A., Savarino, S. J., Guers, L. D., Levine, M. M. \& Tacket, C. O. (1995). Heterogeneity of enteroaggregative Escherichia coli virulence demonstrated in volunteers. J Infect Dis 171, 465-468.

Nataro, J. P., Steiner, T. \& Guerrant, R. L. (1998). Enteroaggregative Escherichia coli. Emerg Infect Dis 4, 251-261.

Pai, M., Kang, G., Ramakrishna, B. S., Venkataraman, A. \& Muliyil, J. (1997). An epidemic of diarrhoea in South India caused by enteroaggregative Escherichia coli. Indian J Med Res 106, 7-12.
Paul, M., Tsukamoto, T., Ghosh, A. R., Bhattacharya, S. K., Manna, B., Chakrabarti, S., Nair, G. B., Sack, D. A., Sen, D. \& Takeda, Y. (1994). The significance of enteroaggregative Escherichia coli in the etiology of hospitalized diarrhoea in Calcutta, India and the demonstration of a new honey-combed pattern of aggregative adherence. FEMS Microbiol Lett 117, 319-325.

Presterl, E., Nadrchal, R., Wolf, D., Rotter, M. \& Hirschl, A. M. (1999). Enteroaggregative and enterotoxigenic Escherichia coli among isolates from patients with diarrhea in Austria. Eur J Clin Microbiol Infect Dis 18, 209-212.

Rich, C., Favre-Bonte, S., Sapena, F., Joly, B. \& Forestier, C. (1999). Characterization of enteroaggregative Escherichia coli isolates. FEMS Microbiol Lett 173, 55-61.

Savarino, S. J., Fasano, A., Robertson, D. C. \& Levine, M. M. (1991) Enteroaggregative Escherichia coli elaborate a heat-stable enterotoxin demonstrable in an in vitro rabbit intestinal model. J Clin Invest 87, $1450-1455$

Schmidt, H., Knop, C., Franke, S., Aleksic, S., Heesemann, J. \& Karch, H. (1995). Development of PCR for screening of enteroaggregative Escherichia coli. J Clin Microbiol 33, 701-705.

Schubert, S., Rakin, A., Karch, H., Carniel, E. \& Heesemann, J. (1998). Prevalence of the "high-pathogenicity island" of Yersinia species among Escherichia coli strains that are pathogenic to humans. Infect Immun 66, 480-485.

Schultsz, C., van den Ende, J., Cobelens, F., Vervoort, T., van Gompel, A., Wetsteyn, J. C. \& Dankert, J. (2000). Diarrheagenic Escherichia coli and acute and persistent diarrhea in returned travelers. J Clin Microbiol 38, 3550-3554.

Sheikh, J., Czeczulin, J. R., Harrington, S., Hicks, S., Henderson, I. R., Le Bouguenec, C., Gounon, P., Phillips, A. \& Nataro, J. P. (2002). A novel dispersin protein in enteroaggregative Escherichia coli. J Clin Invest 110, 1329-1337.

Smith, H. R., Cheasty, T. \& Rowe, B.(1997). Enteroaggregative Escherichia coli and outbreaks of gastroenteritis in UK. Lancet 350, 814-815.

Spencer, J., Smith, H. R. \& Chart, H. (1999). Characterization of enteroaggregative Escherichia coli isolated from outbreaks of diarrhoeal disease in England. Epidemiol Infect 123, 413-421.

Svenungsson, B., Lagergren, A., Ekwall, E., Evengård, B., Hedlund, K. O., Kärnell, A., Löfdahl, S., Svensson, L. \& Weintraub, A. (2000). Enteropathogens in adult patients with diarrhea and healthy control subjects: a 1-year prospective study in a Swedish clinic for infectious diseases. Clin Infect Dis 30, 770-778.

Vial, P. A., Robins-Browne, R., Lior, H., Prado, V., Kaper, J. B., Nataro, J. P., Maneval, D., Elsayed, A. \& Levine, M. M. (1988). Characterization of enteroadherent-aggregative Escherichia coli, a putative agent of diarrheal disease. J Infect Dis 158, 70-79.

Vial, P. A., Mathewson, J. J., DuPont, H. L., Guers, L. \& Levine, M. M. (1990). Comparison of two assay methods for patterns of adherence to HEp-2 cells of Escherichia coli from patients with diarrhea. J Clin Microbiol 28, 882-885.

Vu Nguyen, T., Le Van, P., Le Huy, C., Nguyen Gia, K. \& Weintraub, A. (2006). Etiology and epidemiology of diarrhea in children in Hanoi, Vietnam. Int J Infect Dis 10, 298-308.

Wanke, C. A., Cronan, S., Goss, C., Chadee, K. \& Guerrant, R. L. (1990). Characterization of binding of Escherichia coli strains which are enteropathogens to small-bowel mucin. Infect Immun 58, 794-800.

Wanke, C. A., Schorling, J. B., Barrett, L. J., Desouza, M. A. \& Guerrant, R. L. (1991). Potential role of adherence traits of Escherichia coli in persistent diarrhea in an urban Brazilian slum. Pediatr Infect Dis J 10, 746-751. 